\title{
LA MODIFICACIÓN FRASEOLÓGICA EN LA OBRA LITERARIA DE ANTONIO GALA
}

\author{
Véselka Nénkova \\ Universidad de Plovdiv "Paisiy Hilendarski” \\ http://dx.doi.org/10.18778/8220-201-4.21
}

\section{Resumen}

En el presente trabajo trataremos de presentar un análisis detallado de los mecanismos de manipulación creativa en el uso de las unidades fraseológicas (UFs) en la obra literaria del renombrado escritor español Antonio Gala. El estudio nos permitirá indagar en las razones de la efectividad discursiva de la modificación fraseológica y señalar las técnicas aprovechadas por el autor. Nuestro objetivo consiste en analizar tanto las UFs localizadas como el tipo de transformación que han sufrido, con el fin de acercarnos a uno de los aspectos más interesantes de la fraseología, la manipulación creativa.

Palabras clave: Fraseología, modificación, desautomatización, literalización.

Abordaremos el estudio de la modificación fraseológica para ofrecer tanto una visión general de este fenómeno lingüístico como algunas particularidades de su configuración y funcionamiento. Entendemos la unidad fraseológica (UF) en un sentido amplio, es decir, incluimos bajo este término tanto las colocaciones y las locuciones como las paremias, las máximas, las citas célebres y las fórmulas rutinarias.

Las recreaciones fraseológicas, llamadas también desautomatizaciones, deslexicalizaciones, modificaciones, manipulaciones, ocasionalismos, neologismos, etc., son producto de la creatividad lingüística de los hablantes que, de forma consciente, transforman las unidades fraseológicas para dotarlas de un sentido novedoso. 
De acuerdo con las clasificaciones de Ruiz Gurillo (1995), Zamora Muñoz (1999), Zuluaga (2001), Corpas Pastor y Mena Martínez (2003), García-Page Sánchez (2008), entre otros, proponemos el análisis de algunas de las modificaciones fraseológicas, encontradas en la obra literaria de Antonio Gala, para ejemplificar los mecanismos de manipulación que motivan un cambio formal o semántico-contextual en las expresiones fraseológicas. No es de extrañar que hayamos centrado nuestro interés en la obra de este autor, ya que la manipulación fraseológica constituye un recurso lingüístico muy productivo en sus escritos. Antonio Gala maneja con maestría el juego de palabras y crea ingeniosos efectos lúdicos a través de las modificaciones fraseológicas.

En la teoría fraseológica las modificaciones creativas se suelen dividir en dos grupos: 1) modificaciones internas y 2) modificaciones externas. Las modificaciones internas son aquellas que se efectúan directamente sobre la estructura formal de las UFs y que pueden afectar al inventario de componentes o a las relaciones que se establecen entre ellos. Las modificaciones externas, por su parte, juegan con el significado traslaticio o literal de una UF (Corpas Pastor, 1996: 235-240).

Como una observación clara en contra de la eventual sospecha de que cualquier modificación puede convertir la UF en una combinación de elementos de la técnica libre del discurso, alegamos aquellas ocasiones en las que la UF desautomatizada no sufre ningún cambio formal, tan solo se utiliza en un contexto atípico. Veamos el siguiente ejemplo:

(1) El tiempo es un verdugo que nos hace a su imagen y semejanza, es decir, pasajeros también ("Los papeles de agua", 2008: 298).

A su imagen y semejanza es una expresión de origen bíblico que Antonio Gala intencionalmente utiliza para explicar cómo el paso del tiempo modela a los seres humanos. Como vemos, la UF no sufre ningún cambio sintáctico, léxico ni gramatical, sin embargo, está utilizada en un contexto atípico, ya que normalmente la expresión a su imagen y semejanza se relaciona con que Dios hizo al hombre a su imagen y semejanza. La UF no se presenta alterada 
en su estructura sino en su combinabilidad ${ }^{1}$. Tal y como se pone de manifiesto a través del ejemplo arriba citado, la manipulación fraseológica no implica necesariamente un cambio formal. La modificación creativa revitaliza y actualiza el contenido de las UFs sin destruir por completo sus características de expresiones fijas.

Entre las modificaciones formales la sustitución léxica es una de las técnicas más utilizadas; dicha modificación se puede llevar a cabo mediante el cambio de uno o más elementos de la UF por medio de un sinónimo, un antónimo o una palabra que no guarda ninguna relación con el componente modificado. En el siguiente ejemplo Gala sustituye el sustantivo pluralizado tortas por el extranjerismo (también pluralizado) brioches y buenas son por el verbo comer en la UF a falta de pan, buenas son tortas 'conformarse con lo que se tiene, si no se ha conseguido algo mejor':

(2) La infeliz María Antonieta, cuando aconsejaba, a falta de pan, comer brioches a los pobres, no sabía cuánto se equivocaba... Después sí se enteró (“Los papeles de agua”, 2008:378).

La sustitución fraseológica se puede llevar a cabo mediante el cambio de un antropónimo por otro. Con la sustitución, motivada por el contexto, se ha conseguido modificar la locución así se las ponían a Fernando VII.

(3) Y alli, en sus arrabales, el día del veinticinco cumpleaños de Carlos lo derrotan (a Francisco de Francia), lo cogen preso y organizan la matanza de la nobleza francesa mayor desde Agincourty Enrique V de Inglaterra. Asíse las ponían a Carlos V ("El pedestal de las estatuas", 2007: 188).

La sustitución aquí está impuesta por el contexto; el autor explica previamente que no pocos hechos importantes durante el reinado de Carlos V no fueron resultado de la decisión personal y premeditada del monarca, sino que más bien fueron acaeciendo forzados por las circunstancias. Mediante el reemplazo de los nombres propios Fernando VII por Carlos V la UF está modificada, aun así, sigue teniendo el significado originario de

1 Término utilizado por Zuluaga (2001: 78). 
'ponderar la extremada facilidad con que se le presenta un asunto a alguien'.

Debido a la amplia vigencia de uso, los refranes y proverbios son idóneos para ser modificados y es fácil que se sustituya más de un elemento en su forma original. La sustitución de los elementos en la estructura de una UF puede incluso remitir a la evocación de otra UF. Fijémonos en el siguiente ejemplo:

(4) Me quedo con la promiscuidad de algunos roedores que, a falta de otra cosa, son capaces de copular hasta doscientas veces en una hora. "A poco tiempo, mucha cara": buen lema (“Los papeles de agua”, 2008: 405).

Sobre la base del refrán Al mal tiempo, buena cara 'hay que mirar las cosas con optimismo', Antonio Gala crea un divertido juego fraseológico, ya que la sustitución de mal por poco y de buena por mucha modifica formalmente la paremia, adaptándola perfectamente al contexto; además, la sustitución en la segunda parte de la UF bimembre desemboca en otra UF tener (mucha) cara 'ser un descarado'.

El procedimiento de modificación por adición de lexemas (llamado también alargamiento, inserción, prolongación o expansión) consiste en un aumento del número de los componentes de una UF mediante la inserción de elementos externos a la misma. Los elementos añadidos pueden ocupar distinta posición: la inicial, la intermedia o la final. La forma más simple de este tipo de modificación es la adición de un solo componente libre que suele vincular la UF con el contexto, precisar o enfatizar el significado de la UF (Zholobova, 2015: 5). Veamos el siguiente ejemplo:

(5) Eso nadie lo dice en una fiesta, porque todos lo saben y se han encogido de antemano de hombros para poder comer en paz y cenar y hacer negocios entre sí con los que seguir estrangulando a los hermanos que no están invitados ("Los papeles de agua”, 2008: 447).

En este ejemplo vemos insertada la locución adverbial de antemano 'con anticipación, anteriormente' en la UF encogerse de hombros 'mostrarse o permanecer indiferente ante lo que alguien oye o ve'. 
La adición de lexemas a las UFs a menudo lleva a la creación de una paradoja. Como señala Vucheva (2008: 65):

La paradoja es un razonamiento basado en dos juicios contradictorios desde el punto de vista formal o en su esencia. [...] la unión inesperada de los contrastes, el absurdo que nace de su incompatibilidad lógica, revelan un sentido unitario y coherente en el referente extralingüístico.

Fijémonos en el siguiente fragmento:

(6) [...] y se volvió de pronto y me tendió los brazos con los ojos muy abiertos y me asió por los míos y me besó en la mejilla izquierda y luego echó a correr como un loco de atary desatar (“Los papeles de agua”, 2008: 77).

Antonio Gala, con su lenguaje sutil e ingenioso, mediante la adición inesperada de un elemento de contraste (desatar) en la UF loco de atar, crea una deslumbrante paradoja: un loco de atar $y$ desatar. Una prueba más de la agudeza del pensamiento de Antonio Gala nos lo proporciona el siguiente ejemplo:

(7) Ante la dificultad de Fernando, tropezó con la colaboración de un paje joven como ella, llamado íñigo de Loyola que, a fuerza de roces y entradas, la dejó en estado de no se sabe si buena o mala esperanza ("El pedestal de las estatuas", 2007: 113).

El escritor ha manipulado, por medio de la técnica de adición de elementos (en este caso se trata de nuevo de un antónimo), la UF en estado de buena esperanza 'estar embarazada': la dejó en estado de no se sabe si buena o mala esperanza. El contraste entre los dos antónimos provoca una ruptura de las expectativas del lector; la presencia del adjetivo buena, sin embargo, lo ayuda a interpretar fácil y correctamente el enunciado irónico.

Las modificaciones gramaticales consisten en el cambio ocasional de aspectos morfológicos o sintácticos de alguno o varios de los elementos de una UF. Según Corpas Pastor y Mena Martínez (2003: 196), la modificación gramatical actúa como epígrafe general bajo el cual se reúnen diferentes alteraciones como la inversión 
de elementos, el cambio de afirmación a negación y el cambio en el número de algún constituyente. A este grupo podríamos añadir también la derivación por medio de sufijos aumentativos y diminutivos, el cambio de modo del verbo, del tiempo, del aspecto, de la modalidad, de la voz, etc. Ilustraremos este tipo de modificaciones con el ejemplo que se ofrece a continuación:

(8) Pero creía que tales invenciones no sucedían en la vida normal. Claro, que a toda cerda le llega su San Martín... ("Los papeles de agua", 2008: 326).

En este ejemplo se produce un cambio de género (cerda en vez de cerdo) impuesto por el contexto, ya que la protagonista es la que está reflexionando sobre su incontenible obsesión por estar con el hombre amado.

Una de las técnicas de modificaciones externas es la de desplazamiento literal que se produce mediante la adición de un comentario basado en la UF original (Nénkova, 2016: 78). En el desplazamiento literal, a diferencia de la técnica de adición de elementos -que es una de las técnicas de modificación formal-, los componentes complementarios no afectan a la estructura de la UF original. La actualización que se realiza del significado de la UF se basa en la lectura literal de alguno de los elementos de la expresión a través de la repetición de este en un comentario adicional. Así, una vez identificada con su significado idiomático, la UF recibe otra interpretación al aplicarse a una situación en la que es posible que tenga un sentido distinto del fraseológico gracias al contexto en el que se pronuncia.

(9) - ¿Nos conocíamos ya? -Ahora sí que estaba perdida. Me ofreció un cigarrillo en una pitillera de oro. Me asía él como a un clavo ardiendo. Pero no ardía aún: me alargó fuego con un mechero naturalmente de oro ("Los papeles de agua”, 2008: 365).

Aquí se produce un desplazamiento literal; el cigarrillo se debe concebir como el clavo al que se agarra la protagonista en la conversación. El verbo arder en la oración adicional, conjugado en imperfecto de indicativo, impone que se haga una lectura literal 
del verbo. La doble lectura del componente verbal de la expresión agarrarse a un clavo ardiendo obliga al lector a hacer una interpretación contextual de la UF.

Hemos encontrado también un caso de desplazamiento del significado fraseológico hacia el significado simbólico de una de las palabras constituyentes de la UF ponérsele a uno la carne de gallina: (10) Simplemente mirar las fotos en las que voy creciendo me pone la carne de gallina. A cada uno se le pone carne de lo que es (“Los papeles de agua", 2008: 61).

En este caso Antonio Gala juega con la palabra gallina de la expresión fraseológica ponérsele a uno la carne de gallina 'erizársele la piel de miedo, impresión o repulsión' aprovechando el significado simbólico que posee la gallina en la cultura española, el de 'persona cobarde', para subrayar el débil carácter y la muy baja autoestima que acarrea la protagonista de la novela.

Son numerosos los ejemplos en que se observa el empleo simultáneo de dos o varios procedimientos de modificación, por ejemplo: adición y reducción de elementos, alusión, fusión de dos UFs, cambios gramaticales y sintácticos, literalización, doble interpretación de los significados -el idiomático y el literal-, desplazamiento literal, etc.

(11) Decidió darse una vuelta por tiendas y por bares. Es comprensible: estaba un poco hasta el colodrillo de cuadros y de piedras... (“Los papeles de agua”, 2008: 312).

Antonio Gala, en este ejemplo, sustituye la palabra coronilla por colodrillo y añade los elementos un poco a la UF estar hasta la coronilla 'estar harto'.

(12) En contra del refrán, tan cazurro y avaro como suelen, la felicidad estará más bien en uno de los cien pájaros que vuelan y no en el que tenemos y retenemos en la mano. Un día, de pronto, alguno de los cien se nos posará en la frente o en el hombro y olfatearemos el gozo de la vida; pero cualquier gesto lo asusta y escapa al aire de todos, como el halcón del otro día, que es lo suyo ("Los papeles de agua", 2008: 128). 
En el fragmento anterior, Antonio Gala cuestiona el significado del refrán Más vale pájaro en mano que ciento volando 'no arriesgar las cosas seguras, aunque sean modestas, por el afán de obtener otras mejores pero inciertas'. El escritor, mediante la alusión y la transformación formal de la paremia, apuesta por la idea de que la felicidad no hay que buscarla en lo seguro, sino en las cosas inciertas y aventureras, aun a riesgo de que cuando se consigan puedan resultar efímeras.

(13) [...] porque el amor no es sólo ciego sino sordo y, en último término, deficiente mental ("Los papeles de agua", 2008: 377).

El significado de la frase el amor es ciego está acentuado con la modificación gramatical mediante la conjunción sino acompañada por no sólo y la adición de los elementos sordo y deficiente mental. (14) De ahí que no hace mucho llegué a la conclusión de que quien está solo, está también mal acompañado ("Los papeles de agua", 2008: 81).

En este ejemplo se invoca la expresión original Mejor solo que mal acompañado. Se trata de un caso de modificación formal (sustitución de lexemas y adición de elementos ajenos a la frase) con la consiguiente actualización del significado, pues la UF modificada pasa a significar lo contrario que la original. En efecto, quien está solo, está también mal acompañado evoca una sensación de vacío y soledad totalmente opuesta al significado de la UF original. La expresión fraseológica manipulada equipara lo negativo de la mala compañía a lo negativo de la soledad.

(15) El calory el dolor son media vida: si renunciamos a ellos, estamos renunciando a la pasión. A la pasión por activa y por pasiva: la vehemencia y el campo de batalla. Y sin batalla vehemente no hay victoria que valga. El hombre a medias da agua para que le den sed; da amor que le correspondan. El hombre entero -el que con naturalidad pasa calor en el verano y le llama de tú al dolor-sabe que todo lo importante de este mundo y del otro se tiene de verdad mientras se busca, y se canta de verdad cuando se pierde. Lo demás 
es jugar, igual que el avestruz, al escondite; cerrar los ojos pero no ver la oscuridad; creer que llueve para regar nuestro jardín: pan seco y hambre para mañana ("El don de la palabra", 1996: 107).

En este ejemplo resaltan dos UFs manipuladas. En primer lugar vemos la sustitución de un elemento por otro en la expresión no hay pero que valga donde se conmuta pero por victoria. En segundo lugar percibimos la alusión a la paremia pan para hoy y hambre para mañana. La interpretación se hace gracias a las claves que nos ofrece el autor: pan y hambre para mañana. Como se puede notar, a veces ni siquiera hace falta aportar la unidad original completa, bastan solo los componentes que permitan al lector recuperar la expresión canónica. En el uso de esta paremia Antonio Gala se sirve de la supresión de componentes (ha omitido para hoy) y también de la técnica de adición de elementos a través de la inserción del adjetivo seco al sustantivo pan.

\section{Conclusiones}

El uso de UFs modificadas genera desconcierto y provoca interés en las obras narrativas de Antonio Gala. El autor juega con el saber compartido con el lector y recurre a modificaciones y alusiones a fraseologismos reconocidos por los hablantes. Por la riqueza que presenta la modificación fraseológica, este recurso llama la atención en la cadena textual y reta al receptor a buscar la forma originaria o la relación entre el sentido figurado y el sentido literal. Se trata de un fenómeno discursivo con valor de intensificación que da cuenta de la originalidad y el ingenio del autor que busca complicidad con los lectores.

\section{Referencias bibliográficas}

Corpas Pastor, G. (1996), Manual de fraseología española, Madrid: Gredos.

Corpas Pastor, G. y Mena Martínez F. (2003), “Aproximación a la variabilidad fraseológica de las lenguas alemana, inglesa 
y española”, ELUA, № 17, [en línea] <http://rua.ua.es/dspace/ bitstream/10045/6154/1/ELUA_17_10.pdf $>$, [fecha de consulta: 20.09.2011].

Gala, A. (1996), El don de la palabra, edición de Isabel Martínez Moreno, Madrid: Espasa-Calpe.

Gala, A. (2007), El pedestal de las estatuas, Barcelona: Planeta.

Gala, A. (2008), Los papeles de agua, Barcelona: Planeta.

García-Page Sánchez, M. (2008), Introducción a la fraseología española. Estudio de las locuciones, Madrid: Anthropos.

Nénkova, V. (2016), La manipulación creativa de las unidades fraseológicas en el lenguaje literario, periodístico y publicitario, Plovdiv: Editorial Universitaria "Paisiy Hilendarski".

Ruiz Gurillo, L. (1995), "En torno a las unidades fraseológicas de Cien años de soledad de G. García Márquez", en J. M. Ruiz et al. (eds.), XI Congreso Nacional de Lingüística Aplicada (Valladolid, 1993), Valladolid: Universidad de Valladolid, 703-713.

Vucheva, E. (2008), Estilística del español actual. Teoría y práctica del estilo, Sofía: Editorial Universitaria "San Clemente de Ojrid".

Zamora Muñoz, P. (1999), "Desautomatización y traducción de expresiones fijas italianas en español”, en Á. Iglesias Ovejero, (éd.), Expressions figées: idiomaticité, traduction, Actes du Colloque International 26-27 novembre, 1998, Université D'Orléans: Presses universitaires D'Orléans, 423-440.

Zholobova, A. (2015), "Manipulación creativa de los bibleísmos fraseológicos en español”, Tonos Digital, № 28, Murcia: Universidad de Murcia, [en línea]

$<$ http://www.tonosdigital.com/ojs/index.php/tonos/article/view/12451/774>, [fecha de consulta: 03. 04.2018].

Zuluaga, A. (2001), "Análisis y traducción de unidades fraseológicas desautomatizadas", PhiN, 16/2001, [en línea] <http:// web.fu-berlin.de/phin/ phin16/p16t5.htm>, [fecha de consulta: 05.05.2018]. 